\begin{tabular}{|c|c|}
\hline Title & $\begin{array}{l}\text { Tumor budding and human chorionic gonadotropin- } \beta \text { expression correlate with unfavorable patient outcome in } \\
\text { colorectal carcinoma }\end{array}$ \\
\hline Author(s) & $\begin{array}{l}\text { Konishi, Y uji; Kawamata, Futoshi; Nishihara, Hiroshi; Homma, Shigenori; Kato, Y asutaka; Tsuda, Masumi; Kohsaka } \\
\text { Shinji; Einama, Takahiro; Liu, Cheng; Y oshida, Tadashi; Nagatsu, A kihisa; T anino, Mishie; Tanaka, Shinya; } \\
\text { Kawamura, Hideki; Kamiyama, Toshiya; T aketomi, A kinobu }\end{array}$ \\
\hline Citation & $\begin{array}{l}\text { Medical oncology, 35(7), 104 } \\
\text { https://doi.org/10.1007/s12032-018-1164x }\end{array}$ \\
\hline Issue Date & $2018-07$ \\
\hline Doc URL & http:/hdl. handle.net/2115/4824 \\
\hline Rights & The final publication is avail able at link.springer.com \\
\hline Type & article (author version) \\
\hline File Information & MedOncol35_104.pdf \\
\hline
\end{tabular}

Instructions for use 


\section{Tumor budding and human chorionic gonadotropin- $\beta$ expression correlate with unfavorable patient outcome in colorectal carcinoma}

Yuji Konishi, ${ }^{1, \#}$, Futoshi Kawamata ${ }^{1, \#, *}$, Hiroshi Nishihara ${ }^{2}$, Shigenori Homma ${ }^{1}$, Yasutaka Kato ${ }^{2}$, Masumi Tsuda ${ }^{3}$, Shinji Kohsaka ${ }^{4}$, Takahiro Einama ${ }^{1}$, Cheng Liu ${ }^{5}$, Tadashi Yoshida ${ }^{1}$, Akihisa Nagatsu ${ }^{1}$, Mishie Tanino ${ }^{3}$, Shinya Tanaka ${ }^{3}$, Hideki Kawamura ${ }^{1}$, Toshiya Kamiyama ${ }^{1}$, Akinobu Taketomi ${ }^{1}$

${ }^{1}$ Department of Gastroenterological Surgery I, Hokkaido University Graduate School of Medicine, Sapporo, Japan, ${ }^{2}$ Genomics Unit, Keio Cancer Center, Keio University School of Medicine, Tokyo, Japan, ${ }^{3}$ Department of Cancer Pathology, Hokkaido University Graduate School of Medicine, Sapporo, Japan, ${ }^{4}$ Department of Cellular Signaling, Graduate School of Medicine, University of Tokyo, Tokyo, Japan, ${ }^{5}$ Conjoint Gastroenterology Laboratory, QIMR Berghofer Medical Research Institute, Brisbane, Australia.

\#Co-first authors

*Correspondence author: Futoshi Kawamata, Department of Gastroenterological Surgery I, Hokkaido University Graduate School of Medicine, Kita-ku, Kita 14, Nishi 7, Sapporo 060-8638, Japan.

E-mail: k-futoshi@cotton.ocn.ne.jp

Phone number: +81-11-706-5927

Acknowledgements: We thank the members of the Department of Cancer Pathology, Hokkaido University Graduate School of Medicine, for helpful discussions. 


\begin{abstract}
Tumor budding is thought to represent a manifestation of epithelial-to-mesenchymal transition (EMT) and it has been correlated with poor patient outcomes in colorectal cancer (CRC). Our group recently demonstrated that human chorionic gonadotropin- $\beta$ (hCG $\beta$ ) modulates EMT in CRC. In the current study, based on the likely relationships between tumor budding and hCG $\beta$ expression, we examined their clinicopathologic significance in CRC. Twenty-eight of 80 (35.0\%) CRC showed tumor budding. Tumor budding significantly correlated with lymph node metastasis $(\mathrm{P}<0.01)$, pathologic stage $(\mathrm{P}<0.01)$, lymphatic invasion $(\mathrm{P}=0.044)$, and vascular invasion $(\mathrm{P}=0.013)$. Thirteen of $80(16.3 \%)$ CRC were hCG $\beta$ positive on immunohistochemistry. More tumor buds were present in the hCG $\beta$-positive cases $(\mathrm{P}<0.01)$, and tumor budding was significantly correlated with hCG $\beta$ positivity $(\mathrm{P}<0.01)$. Cases with both tumor budding and hCG $\beta$ expression had the poorest prognosis compared with all other groups $(\mathrm{P}<0.01)$. In conclusion, tumor budding and hCG $\beta$ expression are closely associated with EMT, and they are independent prognostic factors in CRC. They identify patients with an "EMT phenotype” who may respond to targeted molecular therapies.
\end{abstract}

Keywords: Tumor budding • Human chorionic gonadotropin • Colorectal cancer • Epithelial-to-mesenchymal transition • Prognostic factor 


\section{Introduction}

Colorectal cancer (CRC) is a major cause of death worldwide, accounting for 693,900 deaths in 2012 [1]. The most important prognostic indicator for CRC is tumor-node-metastasis (TNM) stage. However, TNM stage does not take into account other features which allow for risk stratification, one of which is tumor budding. Tumor budding is defined by the presence of individual tumor cells and/or small clusters of tumor cells at the invasive front [2]. Tumor budding is considered to be the first step in metastasis, as budding cells are thought to migrate through the extracellular matrix, invade lymphovascular structures and form metastatic deposits in lymph nodes at distant sites [3]. Indeed, tumor budding at the invasive front has been associated with lymph node metastasis, distant metastasis and increased risk of relapse [4-8]. In the process of tumor progression, epithelial-to-mesenchymal transition (EMT) is the initial step of invasion and metastasis, and several transcription factors such as Snail, Slug and Twist are involved. They decrease E-cadherin expression and increase $\mathrm{N}$-cadherin and fibronectin expression, resulting in a mesenchymal phenotype [9, 10]. Similar molecular findings are seen in tumor budding [11, 12], suggest tumor budding is a form of EMT.

Human chorionic gonadotropin (hCG) is a glycoprotein hormone that consists of two polypeptide subunits ( $\alpha$ and $\beta$ ) [13]. hCG has traditionally been used as a marker for pregnancy, pregnancy-associated disorders and gestational trophoblastic disease, but it is also secreted in non-trophoblastic malignancies including colorectal, gastric, and pancreatic carcinomas [14-16]. The ectopic production of the free $\beta$ subunit, hCG $\beta$, in the absence of the $\alpha$ subunit is a recognized phenomenon in the aforementioned epithelial tumors. According to several reports, hCG $\beta$-secreting tumors are more aggressive, radioresistant, and have a greater propensity to metastasize $[14,17]$. Of note, hCG $\beta$ shows significant homology with transforming growth factor $\beta$ (TGF $\beta$ ) [18], a major driving molecule in EMT, and we have recently shown hCG $\beta$ modulates EMT in CRC via the TGF $\beta$ signaling pathway [19]. 
Based on the likely relationships between tumor budding and hCG $\beta$ expression, we examined these features and their correlations with clinicopathologic parameters in 80 CRC.

\section{Materials and methods}

\section{Human CRC samples}

Eighty patients with invasive CRC who underwent radical surgery at Hokkaido University Hospital between 2002 and 2004 were included in the study. Patients were followed up at one- to six-month intervals until death or 31 December 2015, whichever was earlier. Patient clinical data are shown in Table 1. Approval was obtained from the Internal Review Board on Ethical Issues of Hokkaido University Hospital, Sapporo, Japan (14-005).

\section{Pathologic analysis and immunohistochemistry}

Formalin-fixed, paraffin embedded blocks from the 80 CRC were retrieved. One representative block containing invasive tumor was selected from each patient. From each block, one section was cut and stained with hematoxylin and eosin (H\&E), and two sections were cut for pan-cytokeratin and hCG $\beta$ immunohistochemistry (IHC). Pathologic evaluation of primary tumor was performed according to the American Joint Committee on Cancer classification (7th edition) [20]. Other pathologic information (e.g. lymph node status) were obtained from the original pathology report.

Tumor budding was defined as isolated single cells or clusters of fewer than five cells [21]. Tumor budding was quantified on the pan-cytokeratin IHC section. Pan-cytokeratin IHC was performed using a mouse monoclonal antibody against pan-cytokeratin (AE1/AE3, 1:100; ACR011B; Biocare medical, Concord, USA). Budding number was determined by counting in the area of maximal budding, over one high-power field (HPF, 400×). Recently, high tumor budding ( $\geqq 10$ ) was reported to be an adverse prognostic factor for disease-free survival and overall survival in Stages I-III CRC [22]. Therefore tumors with more than 10 
foci of budding per HPF were designated budding positive, otherwise they are designated budding negative.

hCG $\beta$ IHC was performed according to manufacturer instructions (Clone A0231, Dako, Tokyo, Japan). Briefly, after deparaffinization and rehydration, tissue sections were incubated with a rabbit polyclonal antibody against hCG $\beta$ (1:350; A0231; Dako, Tokyo, Japan), followed by reaction with a dextran polymer reagent combined with secondary antibodies and peroxidase (Envision/HRP; Dako, Tokyo, Japan). All assessments were made on viable tumor at $400 \times$ magnification. Tumors with cytoplasmic or membranous staining of more than five epithelial cell clusters were designated hCG $\beta$ positive [19], otherwise they were designated hCG $\beta$ negative.

\section{Statistical analysis}

We used $\chi^{2}$ test or Fisher's exact test to examine correlations between tumor budding, hCG $\beta$ expression, and clinicopathological data. Survival curves for patients were constructed using the Kaplan-Meier method. Two-tailed Student's t-test was used to compare differences between two groups. Prognostic implications of tumor budding and hCG $\beta$ expression were analyzed by Cox univariate and multivariate proportional hazards models. The results were expressed as mean \pm SD. Ekuseru-Toukei 2012 software for Windows was used for analysis (Social Survey Research Information Co. Ltd., Tokyo, Japan). Significance level was set at P $<0.05$.

\section{Results}

\section{Correlations between tumor budding, hCG $\beta$ expression and clinicopathologic}

\section{parameters}

The results are summarized in Table 2. Twenty-eight of 80 (35.0\%) CRC were budding positive (Fig. 1a, 1b). Budding number ranged from 0 to 34 (mean \pm SD, $8.9 \pm 8.5$ ). Tumor 
budding was significantly correlated with lymph node metastasis $(\mathrm{P}=0.006)$, pathologic stage $(\mathrm{P}=0.006)$, lymphatic invasion $(\mathrm{P}=0.044)$, and vascular invasion $(\mathrm{P}=0.013)$. Thirteen of 80 (16.3\%) CRC were hCG $\beta$ positive (Fig. 1c). hCG $\beta$ positivity significantly correlated with histologic grade $(\mathrm{P}=0.031)$, lymph node metastasis $(\mathrm{P}=0.021)$, pathologic stage $(\mathrm{P}=$ $0.021)$ and lymphatic invasion $(\mathrm{P}=0.011)$. In all 13 hCG $\beta$-positive $\mathrm{CRC}$, hCG $\beta$-expressing cells were present at the invasive front of the tumor (Fig. 1d), and in 10 out of 13 cases (76.9\%), hCG $\beta$ expression was identified in tumor buds. Expression of hCG $\beta$ by tumor budding (Fig. 2a, 2b) was detected in 11 of 80 (13.8\%) CRC and correlated with lymph node metastasis $(P=0.038)$ and pathologic stage $(P=0.038)$. Several studies have demonstrated that left- and right-sided colon cancers are genetically distinct [23, 24]. We therefore compared tumor budding and hCG $\beta$ expression with tumor location (left- and right-sided), but no significant differences were observed. Budding number was significantly higher in hCG $\beta$-positive CRC $(16.0 \pm 8.2$ vs $6.7 \pm 7.2)$, and there was a significant correlation between tumor budding and hCG positivity (Table 3) $(\mathrm{P}<0.01)$.

\section{Correlations between tumor budding, hCG $\beta$ expression and patient survival}

There was a trend that budding-positive CRC had an unfavorable prognosis compared with budding-negative CRC, although the result was not statistically significant (Fig. 2c). hCG $\beta$-positive CRC had significantly poorer prognosis compared with hCG $\beta$-negative CRC (Fig. 2d) $(\mathrm{P}=0.02)$. CRC with both tumor budding and hCG $\beta$ expression had the poorest prognosis compared with all other groups (Fig. 2e) $(\mathrm{P}<0.01)$. To further assess the significance of tumor budding and hCG $\beta$ expression, we performed univariate analysis using the Cox proportional hazards model. Vascular invasion, hCG $\beta$ expression, and tumor budding with hCG $\beta$ expression were significantly correlated with poor survival (Table 4). We then performed multivariate analysis to exclude influence by other factors. Tumor budding with hCG $\beta$ expression remained an independent predictor of poor survival (Table 4). 


\section{Discussion}

In this study, we examined the clinicopathologic implications of tumor budding and hCG $\beta$ expression in CRC. Our findings suggest these two factors play a significant role in the progression of CRC, and there is an association between tumor budding and hCG $\beta$ expression at the invasive front. Notably, the group of patients showing both tumor budding and hCG $\beta$ expression had the poorest overall survival in comparison with the other groups. This group was more likely to have lymph node metastases and present at a higher pathologic stage. If this trend is confirmed with a larger patient cohort, tumor budding and hCG $\beta$ expression may be used as a prognostic marker in CRC.

Based on these results, we propose that tumor budding with hCG $\beta$ expression is a novel prognostic marker in CRC. If pathological evaluation of the surgical specimen reveals both tumor budding and hCG $\beta$ expression, these patients may require more aggressive treatment. Moreover, if both tumor budding and hCG $\beta$ expression are detected in an endoscopically resected specimen, they may indicate a latent risk for lymph node metastasis, with the requirement of lymph node dissection even if endoscopic resection is complete.

The current consensus recommends tumor budding should be evaluated on H\&E, since the vast majority outcome data are based on H\&E assessment [25]. However, in some situations (e.g. marked peritumoral inflammation), tumor buds are difficult to identify among reactive stromal cells. In our study we therefore used both H\&E and pan-cytokeratin IHC to visualize the tumor buds. It remains to be clarified whether tumor bud counts obtained via this approach have the same prognostic impact as tumor buds identified on H\&E alone.

Although tumor budding may represent a manifestation of EMT, this hypothesis is not validated as the mechanisms by which budding cells detach from the main tumor are not clear. Previous gene expression studies have shown that the invasive front of CRC shows higher expression of $\mathrm{Wnt} / \beta$-catenin target genes and upregulation of NF- $\mathrm{BB}$ target genes 
compared with the tumor center [26, 27]. In a recent study, dissected budding cells are shown to display an EMT-like signature with activation of both TGF $\beta$ and Wnt signaling [28]. We recently showed hCG $\beta$ induces EMT through TGF $\beta$ receptor activation, and demonstrated the significance of TGF $\beta$ signaling in CRC [19]. Our current study further supports the hypothesis of a close relationship between tumor budding and EMT.

hCG $\beta$ expression in tumor budding represents a potential therapeutic target. In metastatic CRC, tumor budding correlates with resistance to epidermal growth factor receptor antagonists [29]. In a clinical trial, hCG $\beta$ vaccine considerably extended the survival of patients with advanced CRC [30]. The targeting of hCG $\beta$-positive budding cells, whether by vaccines or recombinant antibodies, may be a therapeutic options for advanced CRC.

Our recent study was the first to suggest a relationship between hCG $\beta$ expression and EMT [19]. We showed that hCG $\beta$-overexpressing CRC cell lines acquire a mesenchymal phenotype, demonstrate increased malignant potential compared with their control counterparts, and show altered expression of EMT-related proteins including E-cadherin, Snail, Twist and phospho-SMAD2. These changes result from activation of the TGF $\beta$ signaling pathway, since they are effectively reversed by TGF $\beta$ receptor inhibitors. Additional evidence exists for hCG $\beta$ signaling through the TGF $\beta$ pathway [31]. High levels of TGF $\beta$ and its receptor are commonly found in CRC [32, 33], hCG $\beta$ shows significant homology with TGF $\beta[18,34]$, and the TGFB1 gene (which encodes TGF $\beta$ ) is located in close proximity to the $C G B$ gene (which encodes hCG $\beta$ ) [35].

We therefore propose the following mechanism [19]. Tumor cells secrete hCG $\beta$, which acts in an autocrine fashion at the invasive front. Binding of hCG $\beta$ to the TGF $\beta$ receptor activates downstream cascades and leads to altered transcription of EMT-related proteins. This induces a morphologic change in the tumor cells, which acquire a mesenchymal phenotype and form tumor buds. The increased malignant potential of these cells allows for distant metastasis. 
In conclusion, we have demonstrated that tumor budding and hCG $\beta$ expression occur commonly in CRC, and tumors showing both features have a poor prognosis. Tumor budding and hCG $\beta$ expression are closely associated with EMT, and may serve as molecular targets in CRC treatment.

\section{Compliance with ethical standards}

Conflict of interest: The authors declare that they have no conflict of interest.

Ethical approval: All procedures performed in studies involving human participants were in accordance with the ethical standard of the institutional and/or national research committee and with the 1964 Helsinki declaration and its later amendments or comparable ethical standards.

Informed consent: Informed consent was obtained from all individual participants included in the study.

Data availability: The datasets generated during and/or analyzed during the current study are available from the corresponding author on reasonable request. 


\section{References}

1. Torre LA, Bray F, Siegel RL, Ferlay J, Lortet-Tieulent J, Jemal A. Global cancer statistics, 2012. CA Cancer J Clin. 2015;65(2):87-108.

2. Mitrovic B, Schaeffer DF, Riddell RH, Kirsch R. Tumor budding in colorectal carcinoma: time to take notice. Mod Pathol. 2012;25(10):1315-25.

3. Lugli A, Karamitopoulou E, Zlobec I. Tumour budding: a promising parameter in colorectal cancer. Br J Cancer. 2012;106(11):1713-7.

4. Ueno H, Price AB, Wilkinson KH, Jass JR, Mochizuki H, Talbot IC. A new prognostic staging system for rectal cancer. Ann Surg. 2004;240(5):832-9.

5. Okuyama T, Oya M, Ishikawa H. Budding as a risk factor for lymph node metastasis in pT1 or pT2 well-differentiated colorectal adenocarcinoma. Dis Colon Rectum. 2002;45(5):628-34. 6. Hase K, Shatney C, Johnson D, Trollope M, Vierra M. Prognostic value of tumor "budding" in patients with colorectal cancer. Dis Colon Rectum. 1993;36(7):627-35.

7. Ueno H, Mochizuki H, Shinto E, Hashiguchi Y, Hase K, Talbot IC. Histologic indices in biopsy specimens for estimating the probability of extended local spread in patients with rectal carcinoma. Cancer. 2002;94(11):2882-91.

8. Bradley CA, Dunne PD, Bingham V, McQuaid S, Khawaja H, Craig S et al. Transcriptional upregulation of c-MET is associated with invasion and tumor budding in colorectal cancer. Oncotarget. 2016;7(48):78932-45.

9. Puisieux A, Brabletz T, Caramel J. Oncogenic roles of EMT-inducing transcription factors. 
Nat Cell Biol. 2014;16(6):488-94.

10. Quail DF, Joyce JA. Microenvironmental regulation of tumor progression and metastasis. Nat Med. 2013;19(11):1423-37.

11. Galvan JA, Helbling M, Koelzer VH, Tschan MP, Berger MD, Hadrich M et al. TWIST1 and TWIST2 promoter methylation and protein expression in tumor stroma influence the epithelial-mesenchymal transition-like tumor budding phenotype in colorectal cancer. Oncotarget. 2015;6(2):874-85.

12. Zlobec I, Lugli A. Epithelial mesenchymal transition and tumor budding in aggressive colorectal cancer: tumor budding as oncotarget. Oncotarget. 2010;1(7):651-61.

13. Cole LA. hCG, the wonder of today's science. Reprod Biol Endocrinol. 2012;10:24.

14. Lundin M, Nordling S, Lundin J, Alfthan H, Stenman UH, Haglund C. Tissue expression of human chorionic gonadotropin beta predicts outcome in colorectal cancer: a comparison with serum expression. Int J Cancer. 2001;95(1):18-22.

15. Louhimo J, Kokkola A, Alfthan H, Stenman UH, Haglund C. Preoperative hCGbeta and CA 72-4 are prognostic factors in gastric cancer. Int J Cancer. 2004;111(6):929-33.

16. Louhimo J, Alfthan H, Stenman UH, Haglund C. Serum HCG beta and CA 72-4 are stronger prognostic factors than CEA, CA 19-9 and CA 242 in pancreatic cancer. Oncology. 2004;66(2):126-31.

17. Butler SA, Ikram MS, Mathieu S, Iles RK. The increase in bladder carcinoma cell population induced by the free beta subunit of human chorionic gonadotrophin is a result of an anti-apoptosis effect and not cell proliferation. Br J Cancer. 2000;82(9):1553-6.

18. Lapthorn AJ, Harris DC, Littlejohn A, Lustbader JW, Canfield RE, Machin KJ et al. Crystal structure of human chorionic gonadotropin. Nature. 1994;369(6480):455-61.

19. Kawamata F, Nishihara H, Homma S, Kato Y, Tsuda M, Konishi Y et al. Chorionic Gonadotropin-beta Modulates Epithelial-Mesenchymal Transition in Colorectal Carcinoma Metastasis. Am J Pathol. 2018;188(1):204-15. 
20. Sobin LH, Compton CC. TNM seventh edition: what's new, what's changed: communication from the International Union Against Cancer and the American Joint Committee on Cancer. Cancer. 2010;116(22):5336-9.

21. Ueno H, Murphy J, Jass JR, Mochizuki H, Talbot IC. Tumour 'budding' as an index to estimate the potential of aggressiveness in rectal cancer. Histopathology. 2002;40(2):127-32. 22. Oh BY, Park YA, Huh JW, Yun SH, Kim HC, Chun HK et al. Prognostic Impact of Tumor-Budding Grade in Stages 1-3 Colon Cancer: A Retrospective Cohort Study. Ann Surg Oncol. 2018;25(1):204-11.

23. Arnold D, Lueza B, Douillard JY, Peeters M, Lenz HJ, Venook A et al. Prognostic and predictive value of primary tumour side in patients with RAS wild-type metastatic colorectal cancer treated with chemotherapy and EGFR directed antibodies in six randomized trials. Ann Oncol. 2017;28(8):1713-29.

24. Kuramochi H, Nakamura A, Nakajima G, Kaneko Y, Araida T, Yamamoto M et al. PTEN mRNA expression is less pronounced in left- than right-sided colon cancer: a retrospective observational study. BMC Cancer. 2016;16:366.

25. Lugli A, Kirsch R, Ajioka Y, Bosman F, Cathomas G, Dawson H et al. Recommendations for reporting tumor budding in colorectal cancer based on the International Tumor Budding Consensus Conference (ITBCC) 2016. Mod Pathol. 2017;30(9):1299-311.

26. Horst D, Budczies J, Brabletz T, Kirchner T, Hlubek F. Invasion associated up-regulation of nuclear factor kappaB target genes in colorectal cancer. Cancer. 2009;115(21):4946-58.

27. Hlubek F, Brabletz T, Budczies J, Pfeiffer S, Jung A, Kirchner T. Heterogeneous expression of Wnt/beta-catenin target genes within colorectal cancer. Int $\mathrm{J}$ Cancer. 2007;121(9):1941-8.

28. De Smedt L, Palmans S, Andel D, Govaere O, Boeckx B, Smeets D et al. Expression profiling of budding cells in colorectal cancer reveals an EMT-like phenotype and molecular subtype switching. Br J Cancer. 2017;116(1):58-65. 
29. Zlobec I, Molinari F, Martin V, Mazzucchelli L, Saletti P, Trezzi R et al. Tumor budding predicts response to anti-EGFR therapies in metastatic colorectal cancer patients. World $\mathrm{J}$ Gastroenterol. 2010;16(38):4823-31.

30. Moulton HM, Yoshihara PH, Mason DH, Iversen PL, Triozzi PL. Active specific immunotherapy with a beta-human chorionic gonadotropin peptide vaccine in patients with metastatic colorectal cancer: antibody response is associated with improved survival. Clin Cancer Res. 2002;8(7):2044-51.

31. Berndt S, Blacher S, Munaut C, Detilleux J, Perrier d'Hauterive S, Huhtaniemi I et al. Hyperglycosylated human chorionic gonadotropin stimulates angiogenesis through TGF-beta receptor activation. FASEB J. 2013;27(4):1309-21.

32. Gulubova M, Manolova I, Ananiev J, Julianov A, Yovchev Y, Peeva K. Role of TGF-beta1, its receptor TGFbetaRII, and Smad proteins in the progression of colorectal cancer. Int J Colorectal Dis. 2010;25(5):591-9.

33. Liu XQ, Rajput A, Geng L, Ongchin M, Chaudhuri A, Wang J. Restoration of transforming growth factor-beta receptor II expression in colon cancer cells with microsatellite instability increases metastatic potential in vivo. $\mathrm{J}$ Biol Chem. 2011;286(18):16082-90.

34. Lehnert SA, Akhurst RJ. Embryonic expression pattern of TGF beta type-1 RNA suggests both paracrine and autocrine mechanisms of action. Development. 1988;104(2):263-73.

35. Fujii D, Brissenden JE, Derynck R, Francke U. Transforming growth factor beta gene maps to human chromosome 19 long arm and to mouse chromosome 7. Somat Cell Mol Genet. 1986;12(3):281-8. 


\section{Figure captions}

Fig 1 Representative examples of (a) H\&E, (b) pan-cytokeratin immunohistochemistry, and (c) hCG $\beta$ immunohistochemistry. Budding cells are highlighted by pan-cytokeratin and, in this case, are also positive for hCG $\beta$. (d) hCG $\beta$-expressing cells are detected at the invasive front. Yellow allows indicate hCG $\beta$-positive cells at invasive front

Fig 2 (a) Tumor budding within the muscularis propria (hCG $\beta$ immunohistochemistry). (b) A higher magnification view of a shows hCG $\beta$ expression within the budding cells. (c) Overall survival of tumor budding-positive patients did not differ significantly from tumor budding-negative patients. (d) Overall survival of hCG $\beta$-positive patients was significantly poorer compared with hCG $\beta$-negative patients. (e) Patients with both tumor budding and hCG $\beta$ expression had the poorest prognosis compared with all other expression groups 

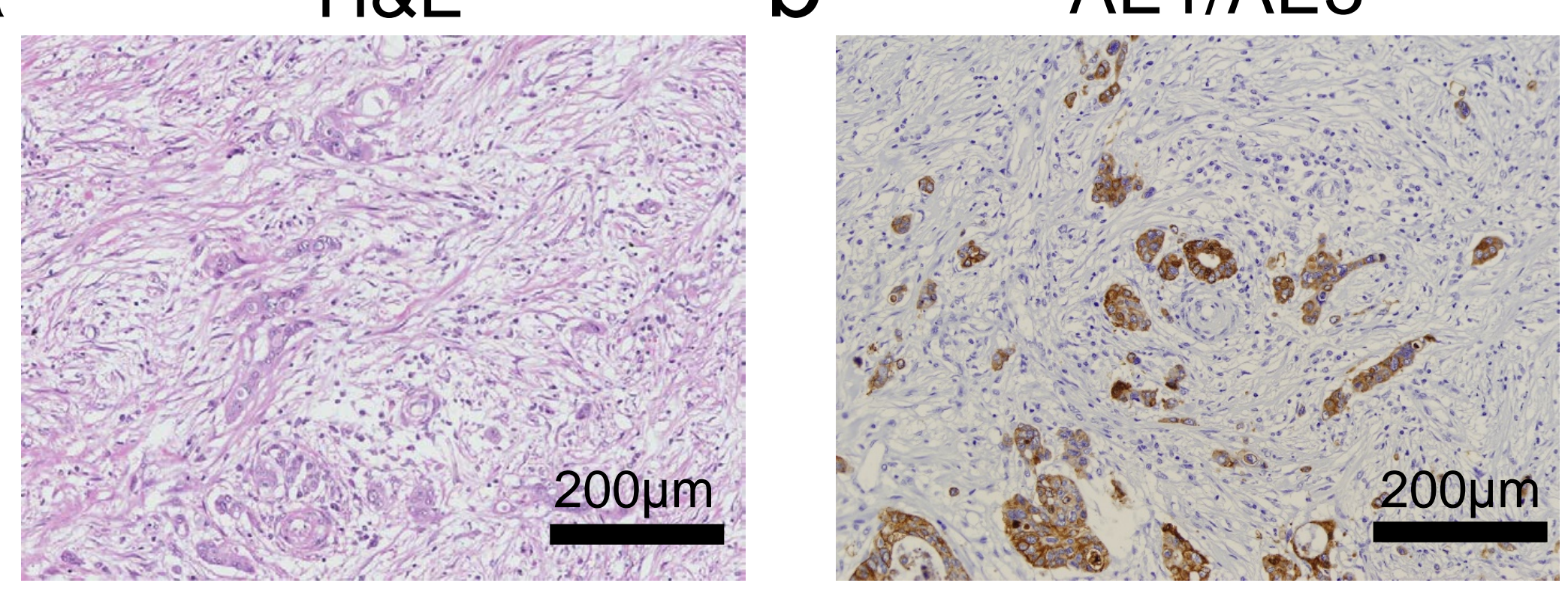

C

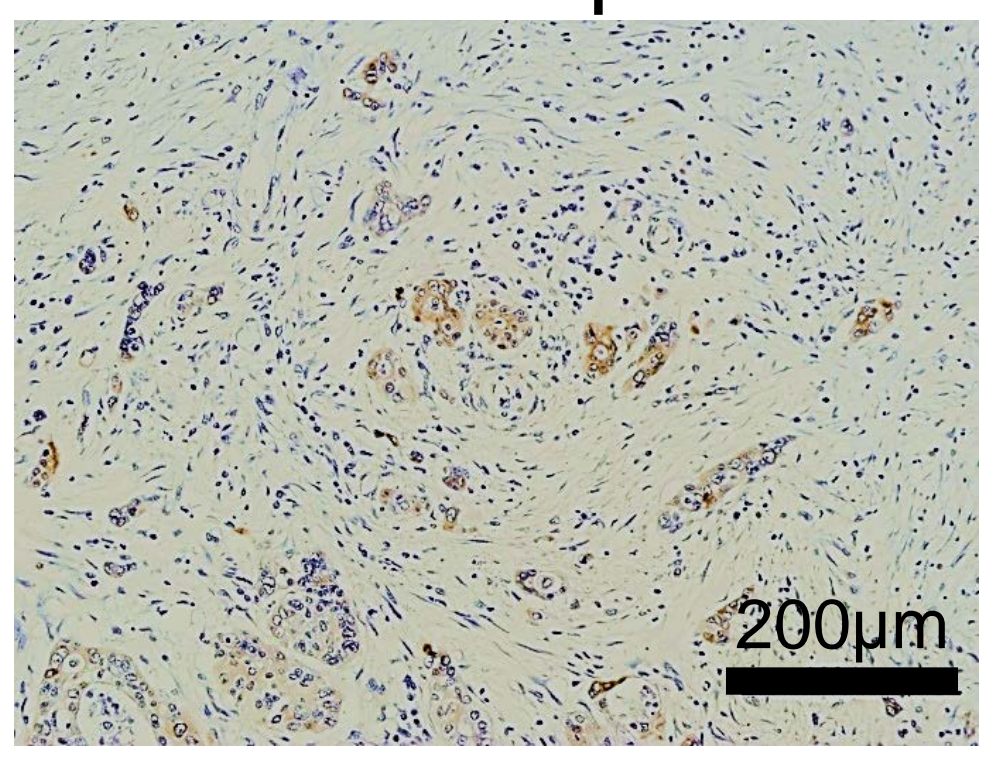

d

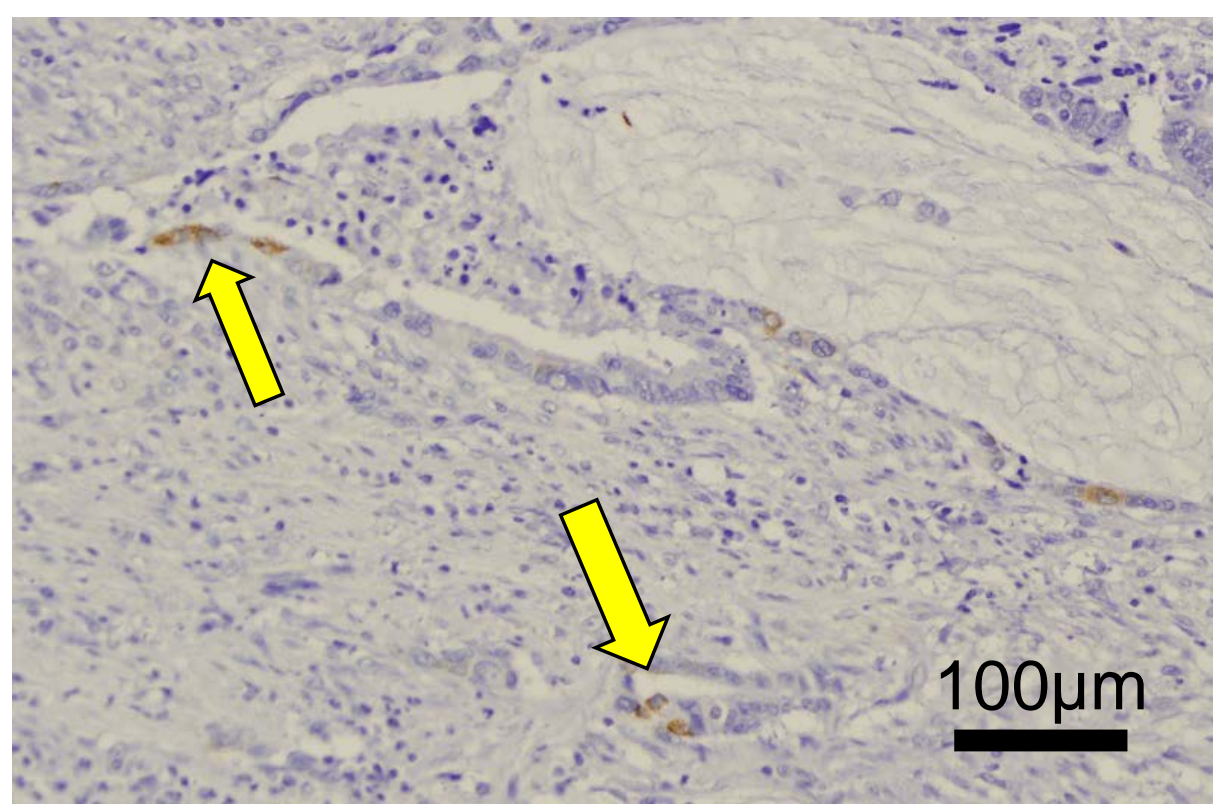




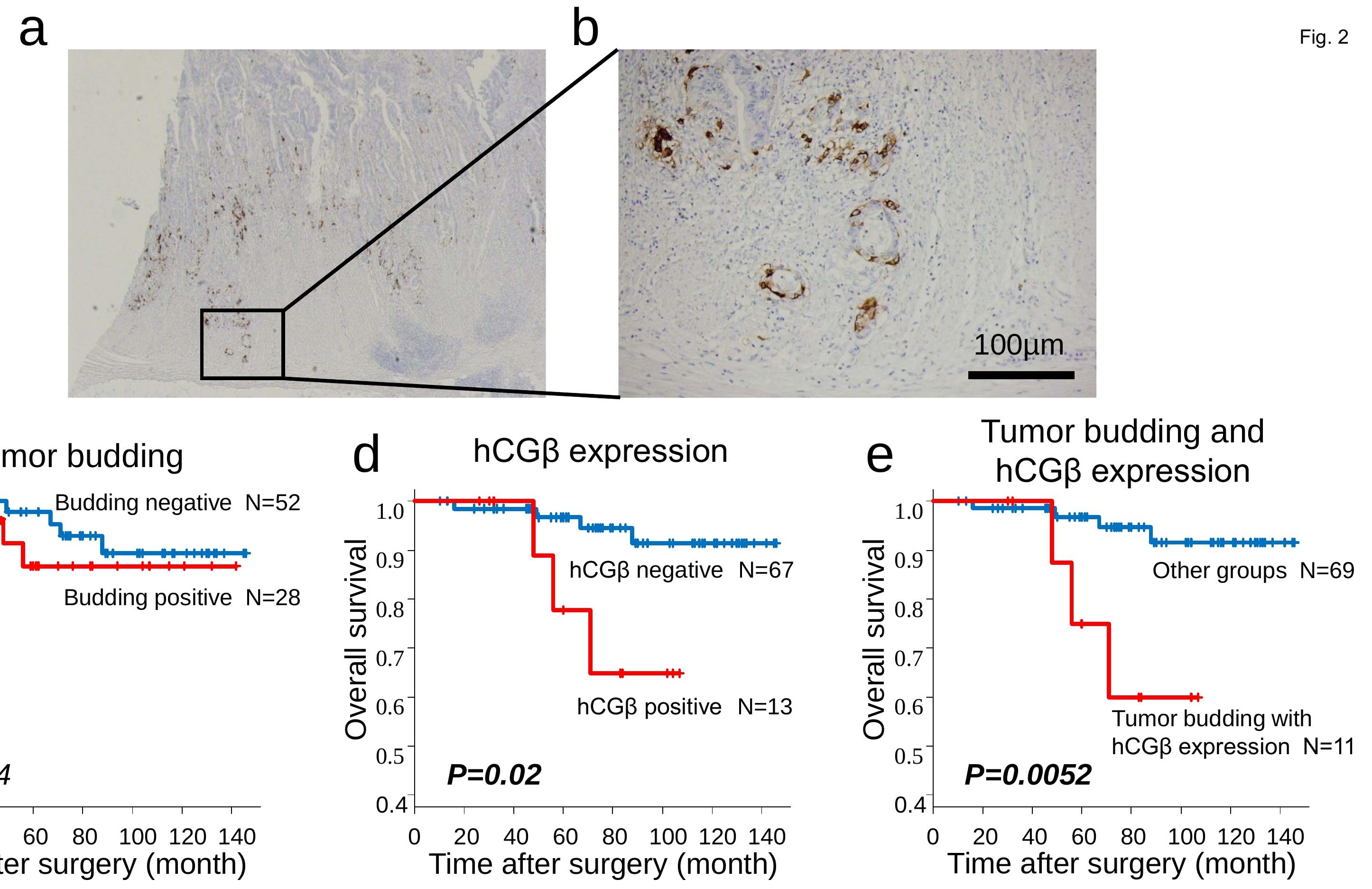


Table 1 Patient clinicopathological characteristics

\begin{tabular}{ll}
\hline Parameter & No. \\
\hline 1. Age (years, mean \pm SD) & $65.2 \pm 12.0$ \\
2. Gender & 34 \\
Male & 46 \\
Female & \\
3.Tumor location & 29 \\
Right & 51 \\
Left & \\
4. Histologic grade & 34 \\
Well differentiated & 46 \\
Moderately/poorly differentiated & \\
5. Resection status & 79 \\
R0 & 1 \\
R1 & \\
6. Pathologic T stage & 17 \\
pT1-2 & 63 \\
pT3-4 & \\
7. Pathologic N stage & 53 \\
pN0 & 27 \\
pN1-3 & \\
8. Overall pathologic stage & 53 \\
I-II & 27 \\
III & $79.0 \pm 33.8$ \\
9. Mean survival (months, mean \pm SD) & \\
\hline
\end{tabular}

SD: Standard deviation 
Table 2 Correlations between tumor budding, hCG $\beta$ expression and clinicopathologic parameters

\begin{tabular}{|c|c|c|c|c|c|c|c|c|c|c|}
\hline \multirow[b]{2}{*}{ Parameter } & \multirow[b]{2}{*}{$\begin{array}{c}\text { Total } \\
(\mathbf{n}=\mathbf{8 0})\end{array}$} & \multicolumn{3}{|c|}{ Tumor budding } & \multicolumn{3}{|c|}{ hCG $\beta$ expression } & \multicolumn{3}{|c|}{$\begin{array}{c}\text { Tumor budding and hCG } \beta \\
\text { expression }\end{array}$} \\
\hline & & $\begin{array}{c}\text { Positive } \\
(\mathbf{n}=\mathbf{2 8})\end{array}$ & $\begin{array}{c}\text { Negative } \\
(\mathrm{n}=52)\end{array}$ & P value & $\begin{array}{c}\text { Positive } \\
(n=13)\end{array}$ & $\begin{array}{c}\text { Negative } \\
(n=67)\end{array}$ & Pvalue & $\begin{array}{c}\text { Yes } \\
(\mathrm{n}=11)\end{array}$ & $\begin{array}{c}\text { No } \\
(n=69)\end{array}$ & P value \\
\hline \multicolumn{11}{|l|}{ 1. Tumor location } \\
\hline Right & 29 & 10 & 19 & 1.000 & 6 & 23 & 0.531 & 5 & 24 & 0.515 \\
\hline Left & 51 & 18 & 33 & & 7 & 44 & & 6 & 45 & \\
\hline \multicolumn{11}{|l|}{ 2. Histologic grade } \\
\hline Well differentiated & 34 & 8 & 26 & 0.064 & 2 & 32 & $0.031^{*}$ & 2 & 32 & 0.106 \\
\hline $\begin{array}{l}\text { Moderately/poorly } \\
\text { differentiated }\end{array}$ & 46 & 20 & 26 & & 11 & 35 & & 9 & 37 & \\
\hline \multicolumn{11}{|l|}{ 3. pT stage } \\
\hline pT1-2 & 17 & 3 & 14 & 0.091 & 1 & 16 & 0.192 & 1 & 16 & 0.441 \\
\hline pT3-4 & 63 & 25 & 38 & & 12 & 51 & & 10 & 53 & \\
\hline \multicolumn{11}{|l|}{ 4. pN stage } \\
\hline pN0 & 53 & 13 & 40 & $0.006^{*}$ & 5 & 48 & $0.021^{*}$ & 4 & 49 & $0.038 *$ \\
\hline pN1-3 & 27 & 15 & 12 & & 8 & 19 & & 7 & 20 & \\
\hline \multicolumn{11}{|l|}{$\begin{array}{l}\text { 5. Overall pathologic } \\
\text { stage }\end{array}$} \\
\hline I- II & 53 & 13 & 40 & $0.006^{*}$ & 5 & 48 & $0.021 *$ & 4 & 49 & $0.038 *$ \\
\hline III & 27 & 15 & 12 & & 8 & 19 & & 7 & 20 & \\
\hline \multicolumn{11}{|l|}{ 6. Lymphatic invasion } \\
\hline Absent & 38 & 9 & 29 & $0.044^{*}$ & 2 & 36 & $0.011 *$ & 2 & 36 & 0.051 \\
\hline Present & 42 & 19 & 23 & & 11 & 31 & & 9 & 33 & \\
\hline \multicolumn{11}{|l|}{ 7. Vascular invasion } \\
\hline Absent & 32 & 6 & 26 & $0.013^{*}$ & 4 & 28 & 0.458 & 3 & 29 & 0.511 \\
\hline Present & 48 & 22 & 26 & & 9 & 39 & & 8 & 40 & \\
\hline \multicolumn{11}{|l|}{ 8. Recurrence } \\
\hline No & 68 & 23 & 45 & 0.744 & 10 & 58 & 0.373 & 9 & 59 & 0.667 \\
\hline Yes & 12 & 5 & 7 & & 3 & 9 & & 2 & 10 & \\
\hline
\end{tabular}


* indicates statistically significant difference $(\mathrm{P}<0.05)$ 
Table 3 Correlation between tumor budding and hCG $\beta$ expression

\begin{tabular}{lccc}
\hline & \multicolumn{3}{c}{ No. } \\
\cline { 2 - 3 } & \multicolumn{2}{c}{ hCG $\boldsymbol{\beta}$ expression } & \\
\cline { 2 - 3 } & Negative & Positive & Total \\
\hline Tumor budding (mean \pm SD) & 50 & 2 & 52 \\
$\quad$ Negative $(3.5 \pm 3.3)$ & 17 & 11 & 28 \\
Positive $(16.9 \pm 7.0)$ & & & \\
Total & 67 & 13 & 80 \\
\hline$\chi^{2} /$ Fisher's exact test $\mathrm{P}<0.01$ & & &
\end{tabular}


Table 4 Univariate and multivariate analysis of patient survival in CRC

\begin{tabular}{|c|c|c|c|c|c|c|}
\hline \multirow[b]{2}{*}{ Parameter } & \multirow[b]{2}{*}{$\begin{array}{c}\text { Total } \\
(\mathrm{n}=\mathbf{8 0})\end{array}$} & \multicolumn{2}{|c|}{ Univariate analysis } & \multicolumn{3}{|c|}{ Multivariate analysis } \\
\hline & & RR (95 \% CI) & P value & RR (95 \% CI) & Hazard ratio & $P$ value \\
\hline 1. Tumor location & & $3.86(0.89-1.39)$ & 0.239 & & NC & \\
\hline Right & 29 & & & & & \\
\hline Left & 51 & & & & & \\
\hline 2. Histologic grade & & $3.92(1.10-2.41)$ & 0.113 & & NC & \\
\hline Well differentiated & 34 & & & & & \\
\hline $\begin{array}{l}\text { Moderately/poorly } \\
\text { differentiated }\end{array}$ & 46 & & & & & \\
\hline 3. Pathologic N stage & & $2.27(1.31-1.94)$ & 0.163 & & NC & \\
\hline pNO & 53 & & & & & \\
\hline pN1-3 & 27 & & & & & \\
\hline 4. Overall pathologic stage & & $2.27(1.31-1.94)$ & 0.163 & & NC & \\
\hline $\mathrm{I}-\mathrm{II}$ & 53 & & & & & \\
\hline III & 27 & & & & & \\
\hline 5. Lymphatic invasion & & $3.56(0.59-1.19)$ & 0.275 & & NC & \\
\hline Absent & 38 & & & & & \\
\hline Present & 42 & & & & & \\
\hline 6. Vascular invasion & & $4.37(1.58-4.21)$ & $0.040^{*}$ & 0.95-13.18 & 3.53 & 0.353 \\
\hline Absent & 32 & & & & & \\
\hline Present & 48 & & & & & \\
\hline 7. Tumor budding & & $1.89(0.65-0.90)$ & 0.343 & & NC & \\
\hline
\end{tabular}


No

Yes

8. hCG $\beta$ expression

No

Yes

9. Tumor budding and hCG $\beta$

No

Yes

RR, relative risk/hazard ratio; CI, confidence interval; NC, not calculable.

28

67

13

$$
6.26(0.82-7.82)
$$

$0.005^{*}$

69

11

\section{* indicates statistically significant difference $(\mathrm{P}<0.05)$}
$6.12(0.74-5.87)$
$0.015 *$
0.08-9.92
5.33
0.054

$1.44-29.34$

6.49

$0.015 *$ 